\title{
HORMONAL CONTROL OF COLLATERAL CIRCULATION
}

\author{
William G. Meffert
}




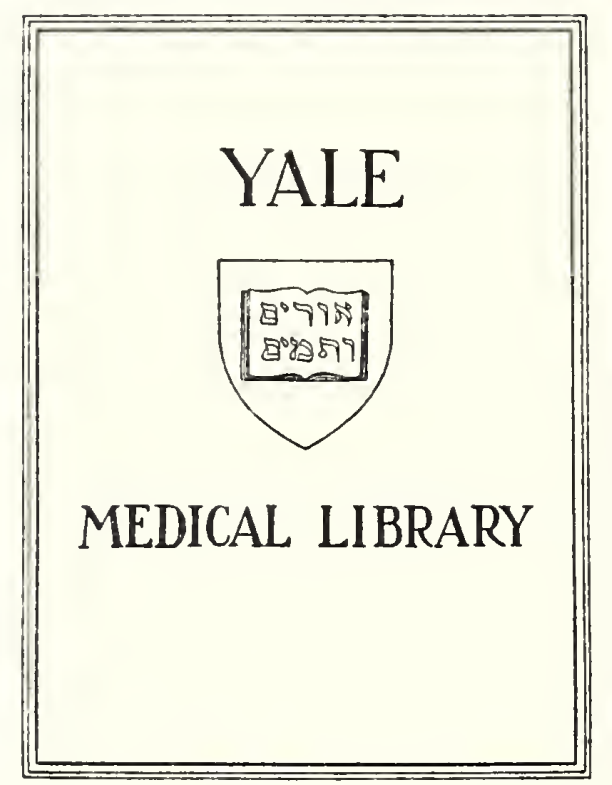


Digitized by the Internet Archive in 2017 with funding from

Arcadia Fund

https://archive.org/details/hormonalcontrolo00meff 

William G. Meffert

Submitted as partial fulfillment of requirements for the degree of Doctor of Medicine, Yale University, School of Medicine.

Department of Pathology 
ALEM

SEP 1962

Wa $415 K A R^{2}-$

$\cdots+12$

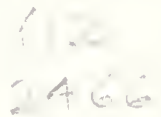


The author gratefully wishes to thank:

Dr.A.A. Jiebow, for providing the facilities, guidance, and kind advice which made it possible to undertake and complete this thesis.

Dr. C. White, for devoting extensive time and effort to the statistical evaluation of the experimental results contained in this thesis.

Dr. H. Soencer, for his help in estimating the effects of cortiscne and growth hormcne on developing bronchial collateral circulation.

The staff of Dr.A.A. Liebow's laboratory, for the many hours of valuable help they contributed to the completion of this project. 

Introduction $\ldots \ldots \ldots \ldots \ldots \ldots \ldots \ldots \ldots \ldots \ldots, 1$

Review of Literature.......................... 2-18

Materia1 and Methods.................... pp. 19-25

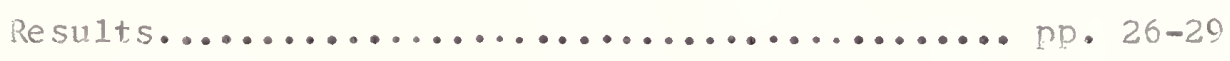

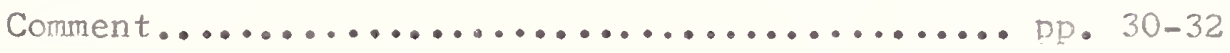

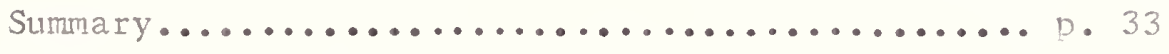

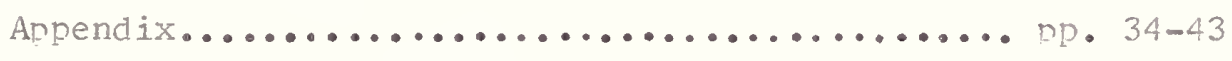

Bibliography.......................... pp. $44-47$ 



\section{Introduction}

Numerous theories have been advanced in an attempt to explain why and how collateral arterial channels develop following ligation or occlusion of a major artery. Mechanica1, neural, chemical and hormonal factors have all been implicated. Interest in collateral circulation in the lung has existed for many years. Enlargement of the bronchial artery following occlusion of the pulmonary artery by such means as embolism or ligation has been observed numerous times. How does this enlargement and development of bronchial collateral circulation occur? Hormones are at least partially responsible, as originally suggested by Liebow et al. 1 and tested by Rosenberg and Liebow. 2

The purpose of this study was to further elucidate the mechanisms of action of cortisone and growth hormone on the development of bronchial collateral circulation in the rat. 


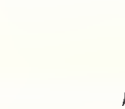


Factors Concerned with the Development of Collateral Circulation

The development of collateral circulation following the occlusion or ligation of a major artery is a long-recognized phenomenon. Two hundred years ago, John Hunter ${ }^{3}$ found that after ligation of the external carotid, the major nutrient artery of the stag's antler, the antler continued uninterrupted growth; also, in time there was a growth of small new vessels around the occluded nutrient artery. How does this collateral circulation develop? There are several theories which attempt explanation. The mechanistic theory:

Studies of arterio-venous fistulas: Holman ${ }^{4}$ invoked this theory to explain why the blood supply to parts of a limb distal to an arterial venous fistula eventually exceeds the normal flow. He believed that the development of collateral flow depended entirely upon the fact that arteries distal to an arterial-venous fistula have a lowered arterial blood pressure and that this 1owered pressure caused collateral enlargement by enabling blood to flow from a high pressure source into a relatively low pressure reservoir bed. The author showed that ligation of the artery immediately distal to the arterial-venous anastomosis prevented development of collateral circulation--presumably by preventing the introduction of lessened resistance into the artery distal to the fistula. Studies utilizing arterial occlusion: After ligation of an artery, Holman ${ }^{4}$ reasoned that high "end pressure" created by the ligation was transformed into a high "lateral pressure" directed into collateral branches. The "lateral pressure" resulted in an increased flow through the collateral vessels which was directed into the same large artery distal to the ligation because of the 
lower pressure present there. North et $21 .^{5}$ noted that following division of significant vessels in the mouse's ear, vessels commun= icating with the occluded arteries distal to the ligations enlarged and that this growth was associated with cellular division of the endothelium and smooth muscle. The authors raised the question of how increased velocity of blood flow through the collaterals stimulated the growth of the cells making up the vessels. Winblad et a1. ${ }^{6}$ noted that during the first four to six seconds following acute occlusion of the superficial femoral artery in dogs, a marked pressure gradient existed across the site of occlusion. By angiography within the same amount of time, collateral vessels were seen arising from the occluded vessel proximal to the block and were noted to communicate with similar vessels joining the major vessel distal to the occlusion. Within three to five minutes, the anterior tibial arterial pressure reached its maximum 1evel. The authors concluded that the development of collateral circulation in the dog appeared to correspond directly with the size of the pressure gradient at the site of occlusion.

Neural factors: Mulvihill and Harvey ${ }^{7}$ brought attention to the importance of the sympathetic nervous system in the development of collateral circulation. The authors discovered that following ligation of an external iliac artery in the dog, a drop of temperature in the corresponding limb could be consistently obtained, but that within a few hours after the ligation the temperature of the extremity would abruptly return to the temperature of the control limb. When lumbar ganglionectomy was performed at the same time as ligation of the corresponding external iliac, no fall in temperature occurred. It was thought by these authors that collateral 

circulation was likely to be accelerated by interruption of the vasomotor reflex and that this principle would be useful as a guide to the treatment of certain cases of gangrene of the extremities.

\section{Chemical influences on collateral circulation:}

The ischemic-tissue theory: Reid's fundamental generalization that arterial channels develop to meet the needs of ischemic tissue forms the background of this theory. Bier believed that vessels beyond an arterial block or beyond an arterial-venous fistula enlarged because of an accumulation of a vasodilator substance in the distal tissues. Lewis 10 also invoked this theory to explain the gradually increased blood supply to the part of a limb distal to an arterial-venous fistula, although he believed this increased blood supply was in part due to a gradual decrease in sympathetic tone and to arterial growth distal to the fistula. Holman ${ }^{4}$ attempted to disprove this ischemic-tissue theory by performing a series of femoral arterial-venous fistulization operations on dogs less than one month after amputation of the corresponding leg. He noted the development of large collateral beds with the reversal or cephalad flow of blood through the artery distal to the fistula despite the fact that in these animals there were no ischemic limbs present. He also showed that the development of collateral circulation was a continuous and progressive process-m both phenomena which the author would not expect to occur if the collateral development were due to an ischemic-tissue elaborating a vasodilator substance.

winblad et al. ${ }^{6}$ found that perfusion of the extremity distal to the occlusion with oxygen-saturated or unsaturated blood pro- 

duced no effect on the development of collateral circulation. This experiment, wile not disproving the ischemic-tissue theory, at least cast doubt ubon the belief that hypoxia served as the vasodilating stimulus.

Hormonal influences on collateral circulation: It is conceivable that a hormone night influence the development of collateral circulation by such means as stimulating or inhibiting the growth of new and old vessels, by guiding new vessels to their destinations, or merely by influencing the amount of vasodilitation and thereby either primarily or secondarily affecting collateral circulation. Granulation tissue: Moon ${ }^{11}$ and Asling et al. ${ }^{12}$ showed that ACrH reduced somatic growth in the intact rat and in the hypophysectomized rat treated with ACTH as compared to the hypophysectomized control. Ghadial1y $y^{13}$ found that cortisone decreased the mitotic activity of rat ear epidermis. That the application of adrenocortical hormones to the skin of rats resulted in thinning and reduction in the number of cell layers composing the stratum germinativum and stratum granulosum had been previously demonstrated by Castor and Baker. ${ }^{4}$ Steroids and ACTH have long been known to affect the formation of granulation tissue including cavillaries present in this tissue. Taubenhaus and Amromin ${ }^{15}$ produced 10 abscesses in rats by the subcutaneous injection of turpentine. Cortisone was found to inhibit the development of fibroblasts and collagen fibers in the walls of abscesses. Shapiro et al. ${ }^{16}$ postulated that cortisone might inhibit granulation tissue by: decreasping the availability of proteins for granulation tissue formation; altering vasomotor tone; 
influencing nervous impulses by interfering with acetylcholine metabolism in peripheral nerves; interfering with the metabolism and function of the central nervous system; or by producing a 10 a 1 effect. That cortisone does exert a local effect was shown by these authors when they found that an abscess induced by the subcutaneous injection of turpentine and cortisone exhibited a sparseness of young capillary buds and a decrease of granulation tissue in its wa11s as compared to a simu1taneous1y induced control abscess. Moderate ischemia and denervation did not interfere with the cortisone effect. Spain et a.1., 17,18 Howes et a1., Baker and Whitaker, ${ }^{20}$ Ragan et a1. ${ }^{21}$ B1unt et a1., 22 and P1otz et a1. ${ }^{23}$ have a11 shown that cortisone systemically administered, interfered with wound healing and, of particular importance, markedly decreased capillary formation in the wound granulation tissue. Spain ${ }^{17}$ among others pointed out that this inhibitory effect of cortisone on the formation of capillaries and othe $r$ components of granulationtissue appeared to be maximal shortly after administration and effective only if given during the early stage of the repair process. No difference between the wounds of cortisone-treated and control animals was noted if cortisone administration was initiated seventy-two hours after wounding. In addition, Baker and witaker ${ }^{20}$ have produced striking interference of granulation tissue formation by direct application of adrenal extract to cutaneous wounds in the rat. The effect was limited to the area of treatment and microscopic sections showed markèd decrease of capillary endothelial cell proliferation compared with controls. Incisional hernias were noted to be developing in five out of six adult male rats five week postoperatively by Rosenberg and 
Liebow ${ }^{2}$ when these animals were maintained on $5 \mathrm{mg}$. cortisone per da.r.

Baxter et al. 24 found that ACTH given patients with various disease conditions produced variable and apparentiy unpredictable responses in the progress of wound healing, epithelization of donor areas, and autograft and homograft survival. However Creditor et a1. ${ }^{25}$ could find 1 ittle or no evidence of granulation tissue, leukocytes, fibroblasts, or proliferating blood vesse1s in skin biopsy wounds of two patients receiving ACTH one week after the biopsy was performed. One week following cessation of ACTH the wounds were re-examined and showed normal healing. Experiments have suggested that growth hormone also influences granulation tissue formation. $\operatorname{Scow}^{26}$ showed that by supplying thyroidectomized-hypophysect omized rats with growth hormone, these anima1s would exhibit a growth of all body tissue. Taubenhaus and Amromin ${ }^{15}$ discovered that rats treated with 100 gamma of somatropin per day formed a more dense wall of granulation tissue in response to the subcutaneous injection of turpentine than did control animals. This granulation tissue, including capillaries, exceeded in abundance that seen in the control animals.

Pulmonary artery occlusion: In 1950 Liebow et a1. 1 ligated the left pulmonary artery and constricted the right pulmonary artery in newborn puppies. The developed bronchial collateral circulation to the side of complete ligation was found to be much more extensive, after a comparable time interval, than the collateral bed developed in adult dogs subjected to the same procedure. 27 This $\mathrm{f}$ inding suggested to the authors that growth hormone, while active on the body as a whole in young puppies, also exerted an 
influence on the developing collateral bed in these young animals. Collateral Circulation in the Lung

The fact that the lungs are supplied with double arterial systems has been known for many years. However, the anatomy of these arterial networks, in particular the communications between the bronchial and pulmonary arterial systems, has been a subject of much debate.

Anatomy of the bronchial arterial system and the nature of broncho= pulmonary arterial communications:

Macroscopic studies: Berry ${ }^{28}$ and Miller ${ }^{29}$ have studied the vascular supply of the bronchial tree in man. Miller stated that there were usually three bronchial arteries: one to the right lung, and two to the left. These usually took origin from the ventral side of the superior descending thoracic aorta and occasionally from the upper intercostal, internal mamary, or subclavian arteries.

According to Verloop, the bronchial arteries of the rat most common $1 y$ arise from the internal mammary artery. These arteries then progress intrapulmonally to the smallest bronchi and give off branches that supply blood to the bronchial walls and branches which ramify as vasa vasorum in the walls of the pulmonary veins. Although capillary anastomoses with the alveolar capillaries of the pulmonary artery were not demonstrated, Verloop believes they are present because the branches of the pulmonary artery filled with fluid which was injected into the bronchial arteries and no precapillary broncho-pulmonary anastomoses were found. 

Histological studies: Weibe $1^{31}$ has studied the histological structure and anatomy of the normal bronchial and pulmonary arterial systems in the rat. He noted that the bronchial arteries have an internal but no external elastic membrane and a media which is relatively thicker than that of the pulmonary artery. The larger bronchi were found to be accompanied by two major bronchial arteries which coursed in the peribronchium close to the pulmonary artery and vein. Smaller bronchial arteries progressed circumferentially around the bronchus.

Since collateral vessels frequently connect the pulmonary and bronchial circulations in rats when the pulmonary arterial pressure is decreased, the question has naturally been raised whether or not these vessels exist in the natural, healthy state. Rakshit ${ }^{32}$ described a vesse 1 communicating between a pulmonary and bronchial artery in both a guinea pig and in a rat. These vesse1s were smooth in contour and without raggedness at their junction with the pulmonary artery. Other vessels similar to these were also seen. These vessels ranged between $70-95 \mathrm{u}$ in diameter. This author believed these vessels were communicating between the bronchial and pulmonary arterial circulations. March and et a1. 33 described macroscopic anastomoses between the two circulations in healthy human lung specimens. Verlocp 30 studied the broncho-pulmonary arterial circulation in rodents and came to the conclusion that precapillary arterial anastomoses were present in the guinea pig but that in the rabbit, mouse, and rat, these vessels normally communicated only at a capillary level. Weibel 31 in 1960 confirmed Verloop's finding that in the norma1, healthy rat, the bronchial and pulmonary arterial circulationsfcommunicate 

only at the capillary level.

Alteration of the anatomy of the bronchial and pulmonary vascular

systems in disease: Packard and Waring ${ }^{34}$ in 1948 showed what

numercus investigators have shown--that the pulmonary artery can

be 1 igated and no gangrene will result because the parenchyma of

the lung receives its nutrition via the bronchial arteries. These

bronchial arteries are greatly altered by chronic pulmonary disease. Early studies: In 1937 Wood and Miller, ${ }^{35}$ with their bismuth

oxychloride injection technique, demonstrated dilatation of the

bronchial arteries and the formation of broncho-pulmonary arterial

connections in association with chronic lung abscess, bronchi-

ectasis, polyserositis, pulmonary tuberculosis, longstanding

rheumatic heart disease, syphilitic heart disease, hypertension, and primary pulmonary malignant neoplasms. In 1938 wright ${ }^{36}$ showed that whew collagenous tissue growth occurs in the lung in association with tuberculosis or a deposit of silica, there is a formation of vascular channels which communicate with bronchial arteries. Primary bronchogenic carcinoma, among other fulmonary tumors, was found to derive its blood supply from the bronchial arterial system. Neither Wood and Miller nor Wright attempted to explain the definitive mechanisms involved in bronchial arterial growth and enlargement. Later investigations of chronic pulmonary diseases: Liebow et al. 37 studied eighteen surgical specimens of human lung containing bronchiectasis and demonstrated marked bronchial artery enlargement and bronchial-pulmonary arterial connections most prominent along fourth order bronchi near areas of marked bronchiectasis. Expansion of the bronchial arterial collateral circliation was later shown not 

necessarily to be accompanied by expansion of the broncho-pulmonary venous circulation. $^{38}$ In another paper, Liebow et al. ${ }^{39}$ described the microscopic changes of bronchial arteries which take place in bronchiectasis and other chronic pulmonary diseases. These arteries develop a prominent inner longitudinal muscle coat which is of greater thickness than the outer circular layer. Prominent circular bands of elastic tissue may appear on both sides of this muscle coat; the inner band being thicker and occasionally interrupted. The thickened walls of these bronchial arteries may reduce the lumen to a slit or even completely occlude the lumen. It was proposed that muscle found in other parts of the diseased lung might be contributed by a splitting-off process from these arteries and subsequent1y intermingle with the muscle of bronchi, distal air passages, 1ymphatics, and interstitial tissue. Increased tension in pathologic lungs was postulated as a cause of this muscle formation and it was thought that this muscle hypertrophy served to reduce collateral flow which possibly did not fulfill a useful function in chronic pulmonary disease.

Pulmonary artery catheferization was utilized by Roosenberg and Deenstra ${ }^{40}$ in the study of chronic pulmonary diseases in humans. These authors found that the oxygen saturation in the pulmonary arteries of the lobes or entire lungs with extensive bronchiectasis was definitely bigher than the systemic venous oxygen saturation. The peripheral end pressure also proved to be high in the diseased areas. They concluded that the bronchial arteries nust be dilated and anastomosing with the pulmonary arteries. It was estimated that the bronchial flow might comprise as much as one third the total cardiac outbut in chronic pulmonary diseases such as bronchiectasis. 

Proposed mechanisms of bronchial arterial enlargement: Mechanisms were proposed for these vascular changes. Mallory ${ }^{41}$ postulated that during the development of bronchiectasis, organizing pneumonitis might occur and precede bronchiectasis. Liebow et a.1. ${ }^{37}$ suggested that budding capillaries might grow out from the bronchial and Dulmonary arteries to supply the resulting granulation tissue. These capillaries might then meet and form anastomoses which persist when healing is complete. According to Liebow et al. 42 in chronic pulmonary diseases, the capillary bed may be decreased by fibrosis and the pulmonary arteries associated with the diseased tissue thickened and partially occluded by fibrosis and subendothelial proliferation of connective tissue. When the counter pressure is thus reduced within the distal capillaries, there is an increase in flow within the bronchial arteries and dilatation of these arteries. The mechanism for further enlargement following this initial mechanical enlargement was not clear but growth hormone was thought possibly to be responsible on the basis of previous experiments. 1

Congenital cardiovascular anomalies resulting in bronchial arterial enlargement: It is wel1 known that great enlargement of the bronchial arteries occurs in congenital anomalies of the heart and great vesse1s which result in $10 \mathrm{w}$ pulmonary arterial pressure, such as tetralogy of Fallot and tricusoid or pulmonic atresia or stenosis. Hales and Liebow ${ }^{43}$ illustrated this marked enlargement of the bronchial arterial system by means of vinylite corrosion casts of the bronchial tree and vascular systems of five autopsy cases of tetralcgy of Fallot and by means of histologic sections of these 

cases and fifteen other cases of congenital pulmonic stenosis or atresia. An explanation for the continued enlargement of the bronchial arteries seen in patients with pulmonic stenosis was given by Rich. ${ }^{44}$ He reported a high incidence of thrombi in the smaller pulmonary arteries in these patients. These thrombi, by further decreasing that pressure in the alveolar capiliaries transmitted through the pulmonary artery, we re thought to increase bronchial collateral circulation into the alveolar capillaries.

Development of pulmonary collateral circulation following ligation of the pulmonary artery: It has long been known that blood from the bronchial arteries is sufficient to support the life of the Iung if there is no excessive back pressure in the pulmonary veins. That man may live many years with pulmonary atresia testifies to this. In $1847 \mathrm{Virchow}^{45}$ demonstrated enlargement of the bronchial arterial system following obstruction of the bulmonary artery to one lobe for a prolonged period of time. That the lumen of the pulmonary artery distal to experimental occlusion by ligation remains patent was shown by Schlaepfer in 1924.46 Vidone et a1. 47 in 1956 confirmed Schlaepfer's finding by demonstrating opacification of the left pulmonary artery following injection of radiopaque media into the bronchial arteries in a study of the hemodynamics induced by ligation of the left pulmonary artery and subsequent cardiopne umon opexy • Studies of respiratory function and hemodynamics following pulmonary artery ligation: Blocmer et a1. 48 Liebow et a1..,9,42 Shedd et a1. 50 and Harrison and Liebow ${ }^{51}$ have studied the respiratory function and 

blood flow in the bronchial arterial system following pulmonary artery ligation in the dog. These authors showed that most of the enlargement of the left bronchial artery occurred during the first few weeks after ligation of the left pulmonary artery. Easily visible precapillary anastomoses developed between the left bronchial and left pulmonary artery distal to its 1igation. When the collateral flow in these enlarged left bronchial arteries was calculated by the Fick principle, Bloomer et a1. found that after four months this flow had increased forty times the normal flow to levels greater than one 1iter per minute. When the pulmonary veins to the left lung were occluded, Liebow demonstrated that the blood pressure in the left pulmonary artery distal to its ligation increased to the mean systemic blood pressure. Between 2.1 and 4.2 seconds after injecting diodrast into the aorta just above the bronchial arteries, the left pulmonary artery beyond the 1igature became radiopaque. Dye studies indicated early recirculation in dogs with a ligated left pulmonary artery. The dye reappeared in the aorta more quickly than normally-.apparently due to collateral circulation through the left side of the heart. Shedd occluded a lobar vein in the normal dog and observed an immediate moderate $\mathrm{rise}$ in intravascular pressure within the 1obe. When this maneuver was performed on another dog with a ligated left pulmonary artery subplying a corresponding lobe, a more abrupt rise in blood pressure occurred within the 1 obe. This phenomenon was attributed to direct access to the pulmonary circulation of blood under systemic arterial pressure--presumably finding access by means of functional anastomoses between the bronchial and pulmonary systems. Harrison and Liebow showed that 

eighteen months after ligation of the dog's left pulmonary artery, the blood flow through the left bronchial arteries had increased to one third the output of the right ventricle and that this collateral blood supply, when not fully saturated, could aid in the absorption of oxygen. The carbon dioxide output of the left lung was found to be less impaired than the ability to take up oxygen. Roh et al. 52 performed functional studies on a patient with a ligation of the left pulmonary artery. They found normal pressure in the right heart and nulmonary artery, a slight increase in cardiac output at rest, and hyperventilation under all conditions. These authors, as Harrison and Liebow, substantiated the fact that the carbon dioxide output was less limited than the oxygen consumption in the left lung.

Structural changes in bronchial artery following pulmonary artery

ligation: The structural changes in the bronchial arteries following division of the left pulmonary artery in rats have been described by Liebow et a1. ${ }^{27}$ and Ellis et a1. 53 Liebow observed that the bronchial arteries became enormously increased in size and tortuosity and that minor vessels became greatly thickened. The walls of the enlarged bronchial arteries consisted of thick layers of smooth muscle fibers with muscle hypertrophy and hyperplasia. Areas of endothelial fibrosis occurred but did not encroach upon the lumen. The internal elastic membrane was thickened and fragmented. B y forty-two weeks post ligation, precapillary anastomoses greater than $50 u$ had developed between the bronchial and pulmonary circulations. Ellis noted detectable enlargement of the left bronchial arteries within three days following ligation of the left pulmonary artery. After the first month little further en- 

largement took place. This author also found that $10 \%$ barium sulfate, which normally filled only the bronchial arteries when injected into the aorta, could be seen in the left pulmonary artery distal to its 1 igation when injected into the aorta two weeks following this ligation. From cast studies, the broncho-pulmonary arterial anastomoses appeared to be located just proximal to the smallest branchioles prior to the alveolar ducts.

Embolization studies: Additional support for the statement that obstruction of the pulmonary artery is of primary importance in producing dilatation of the bronchial arterial system was furnished by Holman et al. 54 These investigators produced embolization of the pulmonary artery and subsequent dilatation of the bronchial artery. The larger the sterile embolus, the greater was found the dilatatin of the bronchial artery and the more numerous the broncho-pulmonary arterial anastomoses. Infected emboli to the pulmonary artery produced more marked and more rapid enlargement of the bronchial artery than sterile emboli. Dilatation of the bronchial artery increased rapidly the first fourteen days after embolization of the pulmonary artery but then remained relatively constant. Mechanisms of bronchial arterial enlargement following pulmonary artery 1igation: The early stages in the development of bronchial collateral circulation in the rat following left pulmonary artery 1igation have been investigated by Weibe1. 31 Definite enlargment of the bronchial arteries was noted at ten days post-ligation with a gradual increase in size up to forty days following thoracotomy. Statistically it was suggested that bronchial artery enlargement occurred in two phases: From two through five days following ligation of the left pulmonary artery, a general enlargement of all the bronchial arteries supplying the left lung took place--most likely a mechanical enlargement due to altered pressure 

gradient resulting from the ligation. However from five through forty days post-operatively, the central branches of the bronchial arteries enlarged more markedly than the peripheral branchings. This second phase of enlargement was accompanied by proliferative changes in the endothelium and media of the bronchial arteries. As this growth of arterial wall and dilatation of arterial lumen took place, signs of new vessel formation in regions of the lung where no granulation tissue could stimulate such a process also occurred. The second phase of arterial grouth and the new vessel formatiom could not be explained on a mechanical basis but were thought to depend ipon other, probably hormonal factors.

The possibility that hormonal factors were capable of influencing the develonment of collateral circulation was investigated by Rosenberg and Liebow ${ }^{2}$ who ligated the right common iliac artery of mature male rats which were subsequent1y divided into a control group, a second group to receive cortisone acetate, and a third group to receive somatropin. All surviving animals were sacrificed at fifteen weeks post-operatively. The animals which had received cortisone were judged to have developed the least evidence of collateral circulation with a probability of error $<.05$. The mature male rats receiving somatropin were found to have developed more collateral circulation than the control animals but the results lacked statistical significance. The authors concluded that cortisone did fartially inhibit the expansion of collateral circulation but were not, under the conditions of the experiment, able to determine whether this inhibition was a direct effect on the vessels or whether it was mediated through other factors, such 
as those producing weight loss and consequently smaller size of this group of rats compared to the control and somatropintreated rats at the conclusion of hormone administration.

This research thesis was designed to eliminate several of the variables inherent in past experiments such as the group weight differences present at the termination of Rosenberg and Liebow's study which introduced complicating factors into the evaluation of the effects of hormones on collateral circulation. It was hoped to thereby clarify the role of somatropin and cortisone in producing alterations of developing collateral circulation in the lung. 

The rat was chosen as the experimental animal for this project because of the minimal individual variances in this species as compared to dogs and other larger research animals, and also because the size, cost, and availability of these animals enabled a large series to be employed further to minimize uncontrollable individual differences. Sixty-six adult male C.D. strain rats were used in this experiment.*

These animals were divided into two equal groups, one group to be sacrificed at the end of fcur weeks, the other group to be sacrificed at the end of eight weeks. Each of these two groups was in turn divided into three equal sub-groups: One to receive cortisone, another growth hormone, and a third sub-group for the control animals. B ecause it was necessary that all animals in each group weigh nearly the same at the time of sacrifice and because it was anticipated that the cortisone-treated rats would lose weight, the control rats gain a moderate amount of weight, and the somatropin-treated rats gain a maximal amount of weight, different initial weights were chosen for each sub-group. ** These rats underwent a left thoracotomy and left pulmonary artery ligation with a 5-0 silk suture. The pulmonary artery was not transected. Following 1igation, the chest wall was closed in layers with 5-0 silk.

The anesthesia and type of positive pressure apparatus best * Rats obtained from the Charles River Breeding laboratories in Brookline, Massachusetts. **See charts one and two in appendix, pp. 3*3, 35. 
for this procedure were arrived at after much experimentation. porter and Small's technique of anesthetizing the rat with pentobarbital intraperitoneally and inserting a plastic tube with a rubber cuff into the trachea for administration of positive pressure oxygen was considered unsatisfactory because three out of $f$ ive rats undergoing thoracotomy with this technique had failed to survive for reasons considered related to intubation. 53 Loring 56 had described an improved positive pressure technique consisting of two Erlenmeyer flasks joined by rubber tubing to a positive pressure mask. One flask contained water and received oxygen from a standard oxygen tank. The water served to humidify the incoming cxygen. From this flask rubber tubes were connected in such a manner that oxygen would then flow directly to the mask entirely or part directiy to the mask and part through the second flask containing ether or thirdly, entirely through the ether flask---depending upon where one clamped of $\mathrm{f}$ the interconnecting rubber tubing. The positive pressure mask consisted of a rounded glass chamber large enough to receive the entire head of the anima1. This chamber had an oxygen inlet tube and an oxygen cutlet tube. The third opening in the chamber-m-wich permitted entrance of the animal's entire head was equipped with a rubber cuff which, according to the author, formed altight seal without constriction around the neck of the rat.

Attempts were made before beginning the experiment to master Loring's technique. However, it was found extremely difficult to adjust the rubber cuff about the animal's neck in a manner which would neither choke the rat nor allow escape of oxygen between the cuff and the animal's neck. A proper fit could be 

obtained only after prolonged adjustments and the use of liberal amounts of grease in attempting to achieve a tight seal. A modification of Loring's technique* was therefore adopted which allowed positive pressure respiration to be applied with minimal adjusting procedures and maximal ease and efficiency. Only the snout of the animal was placed in the chamber and the rubber cuff was placed around the bony skull anterior to the orbits. This rubber cuff fitted very snugly around the bony skull without producing airway obstruction and secured a tightly sealed positive pressure chamber. A C clamp fixed to the operating board with a second clamp was placed around the animal's neck and the screw turned down until it reached the level of the rat's mandible. The $\mathrm{C}$ clamp prevented the animal's snout from sliding backwards out of the chamber when positive pressure was applied. Oxygen entered the chamber through a small polyethylene tube after either bypassing the ether jar, or with some or all of the gas passing through the ether jar---depending unon where the rubber tubes were clamped. Intermittent positive pressure was applied by the surgeon during the thoracotomy by stepping on the bulb which caused the ballon valve to distend and prevented the oxygen-ether mixture from escaping from the chamber.

Before undergoing thoracotomy, the animals were anesthetized with ether and then placed in the positive pressure apparatus by means of which the ether anesthesia was continued. By avoiding barbiturates and keeping the anesthesia on a light plane, postoperative recovery to a fully conscious state was usually achieved in less than five minutes.

*See photograph in appendix, p. 36. 

of the sixty-six animals undergoing thoracotomy fifty-eight survived. The day following operation, injections were begun as follows: All cortisone sub-group animals received $5 \mathrm{mg}$. cortisone acetate (Cortone) ${ }^{\frac{1}{*}}$ intramuscularly each day for two weeks; thereafter injections of $5 \mathrm{mg}$. cortisone acetate were given each ciay, every other day, or every third day depending upon when weight loss was needed to approach the weights of the other sub-groups.

Al1 somatropin subgroups animals received.1 mg. of growth hormone ${ }^{* *}$ intramuscularly per day.

Each animal was weighed every other day beginning one week postoperatively and weights were foljowed by means of charts. *** The weights of the animals were controlled by weighing out specific amounts of ground meal to those subgroups showing a tendency for excessively rapid weight gain. The weights of cortisone subgroup rats were controlled only by varying their hormone dosage.

At four weeks and eight weeks following 1igation, the casting procedure was carried out as follows: At exactly four and eight weeks following pulmonary artery ligation, the four and eight week groups respectively were sacrificed by anesthetizing the anima1s individually in a bell jar containing ether-saturated sponges. While anesthetized, the thorax was opened on the right side by a parasternal incision and $0.5 \mathrm{cc}$. heparin was injected into the right ventricle. The left hemithorax was not entered and its pleura was kept intact. After allowing five minutes for anti-

*Donated by Merk and Company, Inc.

**Supplied by the Endocrinolcgy Study Section, National Institute of Health. $* * *$ See appendix, pp. 34, 35 

coagulation to take place, the heart was amputated up to the orifices of the pulmonary artery and aorta to exsanguinate the anima1. Following this, the ascending aorta was ligated with 5-0 silk. The neck and upper extremities were then tied of with heavy twine to prevent injection of tissue distal to these ligatures. Finally the abdominal aorta was exposed and cannulated through a transverse abdominal incision. The injection technique then carried out was similar to that previously used by Narat et a1. 57 Puckett and Neumann, and Liebow et a1. 59 One large batch of $7 \%$ vinylite in acetone injection media* was prepared prior to the casting procedures and was used for all casts. The perfusion of the aorta proceeded consecutively with water, air, acetone, and air, each for one minute followed by perfusion with $7 \%$ vinylite in acetone for one and one-half minutes, a wait of one minute, then perfusion with the same vinylite mixture for two minutes. After a period of ten minutes, the aorta was finally perfused for five additional minutes with $28 \%$ vinylite in an attempt to minim mize shrinkage and to more completely fill the aorta with plastic. Each injection was performed with a pressure of $250 \mathrm{~mm}$. $\mathrm{Hg}$. kept constant by means of a mercury escape valve. Following injection, the thorax was strioped of skin and removed from the animal by transecting the spinal colum low in the neck and again just below the diaphragm.

The thorax was then suspended in a vacuum jar as described by Moo1ten, Narat et a.1. 57 and Liebow et a1. 59 This vacuum jar contained two openings in the top. Through the first the *VYHH specification No. 1, made by Union Carbon and Carbide Chemical Corp., Bakelite Division, 437 MacCorkle Ave., South Charleston, West Va. 
lumen of trachea commicated with the room air; through the second a suction line was attached which was in series with a mercury manometer. The lungs were inflated in the jars and the negative pressure was maintained at a constant $-10 \mathrm{~mm}$. Hg. A cast of the trachea and bronchial tree was obtained by pouring $28 \%$ vinylite down the trachea once the lungs had been inflated. Suction was maintained for twenty-four hours. Following this period, the thoraxes were removed from the bell jars and the plastic allowed to harden for seven days. The thoraxes were then placed in concentrated HCL for forty-eight hours after first binning the cast of the aorta to the brcnchial tree cast. The casts were then washed for twenty-four hours in running water and dried thoroughly in air. Finally the casts were defatted with petroleum ether. Every effort was made to standardize each of the procedures and to avoid trauna to the casts.

The size and extent of the left bronchial arterial enlargement was estimated by the visual examination of three independent observers. The casts were coded during this technique and all the subgroups were intermingled so as to achieve maximal objectivity. The following classification system was used for ranking the casts:

- No injection of the bronchial artery

1 Injection of the trunk bronchial artery on $1 y$

2 Complete injection of the trunk bronchial artery, but the artery is delicate and has few segmental and no subsegmental branchings

3 Complete injection of the trunk artery with filling of many segmental arteries

4 As 3 except with subsegmental bronchial arterial injection

5 Complete filling of the trunk artery with filling of many segmental and subsegmental arteries and injection of the precapillary broncho-pulmonary arterial anastomoses as we 11 


$$
\text { - }
$$


The casts ${ }^{*}$ were arranged in each division of the classification as to size of the injected bronchial arterial system and complexity of this system; becoming increasingly larger and more complex from the first to the lastldivision, 1-5. The statistical significance of this scoring by rank was then determined by the use of White's adaptation of the Wilcoxon significance test. 61 The critical point of significance accepted for the rank sums was $5 \%$ for the experiment. Actual1y, the 5\% point was not strictly true to name since the test of significance was more stringent than a $\mathrm{P}$ of 0.05 would indicate.

Each observer judged the coded casts by visual examination twice on two separate occasions several weeks apart. Correlations between the first and second readings and between the rankings of the three observers were derived by application of Spearman's rank correlation technique. 62

Following visual scoring, the specimens were dismanteled and the casts of the bronchial arterial systems were weighed. In an attempt to minimize the weight differences caused by variations in length of the left bronchial artery or arteries before reaching the left bronchus, each cast was sectioned where these arteries first touched the cast of the left bronchus and only the cast distal to this site was weighed. The " $t$ " test was utilized in the statistical analysis of these weights. The correlation between the readings of each observer and the ranking of the casts by weight was determined by the application of Spearman's ranking tecnhique.

* Photographs of these casts are seen in appendix, pp. 37, 38. 

Results

Operative mortality was seven percent for all the subgroups except for the eight week control group. This was the first subgroup to undergo thoracotomy and four out of twelve animals died postoveratively as a direct result of technical errors. Therefore, this subgroup was composed of only eight animals. All other subgroups were initia11y composed of ten animals surviving ligation of the left pulmonary artery. One or two rats from each subgroup were subsequently dropped from the experiment either because of evidence of pneumonia or because during the casting procedures technical difficulties resulted in an unsatisfactory cast of the animal's aorta and bronchial arterial tree.

Because a difference in final weights between control rats and rats treated with cortisone and somatropin had introduced a complicating factor in attempting to compare the development of collateral circulation between the groups in kosenberg and Liebow's work, ${ }^{2}$ special effort was made to equalize the final weights in a11 subgroups in the four week group and in the eight week group.* Since little information was available on the growth curves of rats treated with somatropin and cortisone, the initial weights had to be selected on a somewhat arbitrary basis. The knowledge that $5 \mathrm{mg}$. of cortisone each day for fifteen weeks had produced an average weight $10 s$ s of 38 grams in the $358 \mathrm{gm}$. male rat in Rosenberg and Liebow's study and that $.1 \mathrm{mg}$. of growth hormone per ciay ${ }^{*}$ * See table one in appendix, $p .39$. and charts one and two in anpendix, pp. $34,35$.

**This information supplied by Dr. A.E. Wilhelmi, Professor of B iochemistry, Emory University. 

should produce a sustained weight gain of approximately $0.5 \mathrm{gm} \$$. per day in the $260 \mathrm{gm}$. mature male rat considerably influenced the choice of the initial weights. Upon following the weights of the animals post-operatively, it was apparent within two weeks that if the final weights were to be equal, the cortisone-treated animals in each group were losing weight too rapidly when receiving $5 \mathrm{mg}$. of cortisone acetate each day. Therefore, this dosage was decreased as discussed in the Material and Methods section. The control rats and the rats treated with $0.1 \mathrm{mg}$. of somatropin each day showed a tendency to gain excessive weight. Therefore in each group, these rats were placed on a 15-30 gram per day ground meal diet which was varied in amount in order to maintain a steady but slower weight gain. The cortisone-treated animals were given unlimited amounts of the same food.

In both groups, the incision site required several weeks longer to heal in the cortisone-treated sub-groups than in other sub-groups. This was to be expected in view of previous work by Spain et a1., Howes et a1., Ragan et a1., ${ }^{19}$ and P1otz et a1. 23 which showed that systemically administered cortisone interfered with wound healing.

The development of collateral circulation was first evaluated by visual examination of the bronchial artery casts using the system explained in the Material and Methods section. * By this method, the four week cortisone animals were found to have developed a significantly smaller collateral circulation than the four week controls. The eight week growth hormone animals were found to have developed a significantly larger collateral circup. 40.

*The results of this test are recorded in table 2 in appendix, 

lation than the eight week control animals. The four week growth hormone group, while showing somewhat greater bronchial arterial injection than the four week controls nevertheless failed the test of significance. The eight week cortisone animals showed a lesser degree of bronchial arterial injection than their controls. This comparison approached, but did not meet a $\mathrm{P}$ leve1 of 0.05 .

Each observer judged the coded casts by visual examination twice. The correlations between the first and second reacings and between the rankings of the three observers are recorded in the appendix. ${ }^{*}$ The fact that all three observers correlated over $98 \%$ on two consecutive observations and that the three observers correlated over $96 \%$ with each other speaks well for the criteria and technique of scoring.

Since the animals of each group averaged nearly the same weight when sacrificed, and the injection media and technique were rigidly standardized, it was felt that the weights of the casts would serve as a second quantity on which judgment of the size of collateral circulation could be based. It is seen that by the weighing technique ${ }^{* *}$, significant differences between the collatera1 development of the four week cortisone group and the four week control grcup as we11 as between the eight week cortisone group and the eight week control group were demonstrated. In addition, by means of an adjusted "t" test, a difference in cast weights between the eight week growth hormone animals and their controls was shown at the $10 \% 1$ evel of significance. This

\footnotetext{
* See tables 3 and 4 in appendix, p. 40. **Results shown in table 5 in appendix, p. Al.
} 

result, however, cannot be accepted as significant because the $P$ value is greater than 0.05 .

Table $6^{*}$ shows the correlation between the readings of each observer and the ranking of the casts by weight. As demonstrated, the correlations were $90-95 \%$ as determined by the Spearman ranking technique.

General tables containing the number designation of a11 animals, the rankings of the casts by each observer, and ranking by the weighing tecnhique are included in the appendix.

*See appendix, p. 41.

** See tables $7,8,9$ in appendix, pp. 42, 43. 



\section{Comment}

It would appear from this experiment that cortisone does significant1y inhibit the develonment of bronchial collateral circulation following left pulmonary artery ligation. The fact that the animals in each group weighed nearly the same at the time of sacrifice rules out the possibility that this effect of cortisone could be brought about entirely by producing a weight loss and therefore smaller animals in this subgroup than in the other subgroups. In fact, a $100 \mathrm{k}$ at the eight week chart ${ }^{*}$ show's that the cortisone animals in this groun were slightly heavier at the time of death than the other animals. However, this small weight difference is mostly likely without significance.

It is interesting that visual gradings of the casts revealed a significant difference between the four week control and cortisone animals but not between the eight week control and cortisone animals. As previously stated, the animals of each cortisone subgroup were given $5 \mathrm{mg}$. of cortisone per day during the first two weeks. This dosage was then decreased by about $50 \%$ for the remainder of the experiment. The dosage reduction, with the accompanying gain in weight of the cortisone subgroups might have enabled these animals to develop a refractory state to cortisone so that this hormone's effect on collateral circulation would be decreased. Such phenomenon has been noted whereby hair follicles were originally maintained in an inhibited state by local annlication of cortisone but after six months reached a refractory state and were no longer inhibited despite the continued local application of cortisone 
to the skin. ${ }^{14}$ However, the demonstration of a significant difference between the eight week control and ccrtisone animals by the weighing technique would indicate that cortisone still exerted an effect eight weeks post-cneratively despite reduced dosase or that residual effects from this hormone were still present even though a refractory state had been reached.

The statistically significant difference between the eight week controls and the eight week growth hormone animals demonstrated by the visual scoring technioue indicates that somatropin does affect the developing collateral circulation in the rat. The fact that all animals in each group averaged nearly the same weight would indicate that this effect is not caused by somatropin producing larger animals which would naturally contain larger bronchial arteries than the smaller animals in the other subgroups. The finding of at least as extensive collaterals in old contro1 rats as in young growing rats in Rosenberg and Liebow's work $^{2}$ suggested that the initial size of potential collateral channels might be a determinant of their ultimate size. The possibility that the initial size of the bronchial arteries may be a determinant of the ultimate size of the collateral circulation cannot be substantiated by this experiment. The cortisone animals in each group averaged over 60 grams heavier than the other animals at the beginning of the experiment and yet were found to have significantly smaller collateral channels than their controls at the conclusion of hormone administration.

Limitation of the food intake would naturally be thought of as a possible hindrance to the growth and develonment of bronchial collateral circulation as we 11 as a means to regulate the ultimate 

size and weight of the control and somatropin subgroups. The precise effect of this dietary limitation on the developing collateral vessta cannot be determined from this experiment; however, its effect was obviously not great enough to prevent the control animals from developing a more extensive collateral circulation than the cortisone-treated animals and not great enough to prevent the development of significantly larger collaterals in the eight week somatropin animals as compared to their controls.

This exveriment indicates that cortisone and matropin do not exert their entire effects on collateral circulation by producing weight changes of the hormone-treated animals and therefore naturally smaller or larger bronchial arteries than are present in the control animals. Whether these hormones introduce systemic alterations in physiology which secondarily effect the bronchial collateral circulation, or whether their effect is mediated directly upon the developing vessels has not been determined. 

Summary

The possibility that cortisone and somatropin influence the development of bronchial collateral circulation following left pulmonary artery ligation in adult male rats was investigated. The weights of the animals were closely regulated post operatively. At the time of sacrifice, the weights of the control, cortisonetreated, and growth hormone-treated rats were comparable. After four weeks of hormone administration, the cortisone animals had developed a significantly smaller bronchial collater circulation than their contro1s. After eight weeks of hormone administration, the cortisone animals were again found to have smaller collaterals than their controls and the somatropin animals had developed significantly larger collateral channels than the control animals.

The mechanisms of action of these two hormones on develoning collateral vessels remains unclear. The entire effect of cortisone and somatropin is not dependent on producing an ultimate difference in weight between the hormone-treated and control animals: Whether cortisone and growth hormone effect the bronchial collateral circulation indirect1y by producing systemic a1terations in physiology, or whether they directly affect the developing vessels has not been determined. 
APPENDIX 



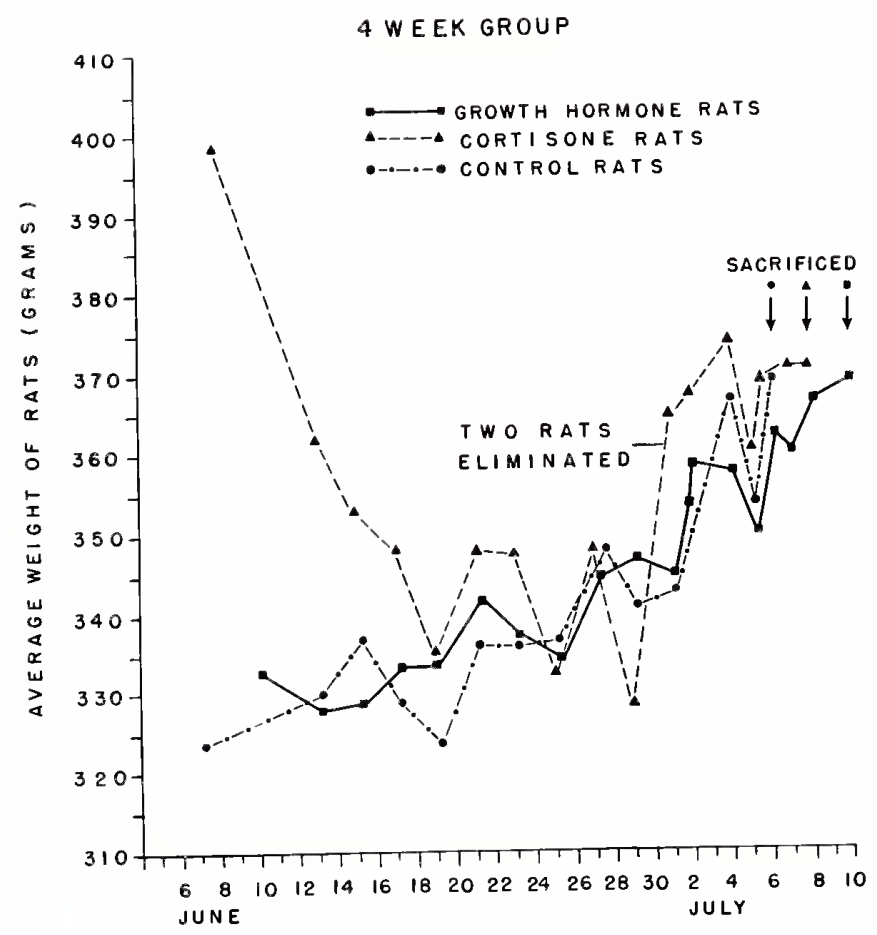

Chart 1

Recording of the average weights of control, cortisonetreated, and growth homone-treated rats in the 4 week group. The ordinate indicates the average weight of each subgroup. The abscissa records the successive days of the exneriment. 

8 WEEK GROUP

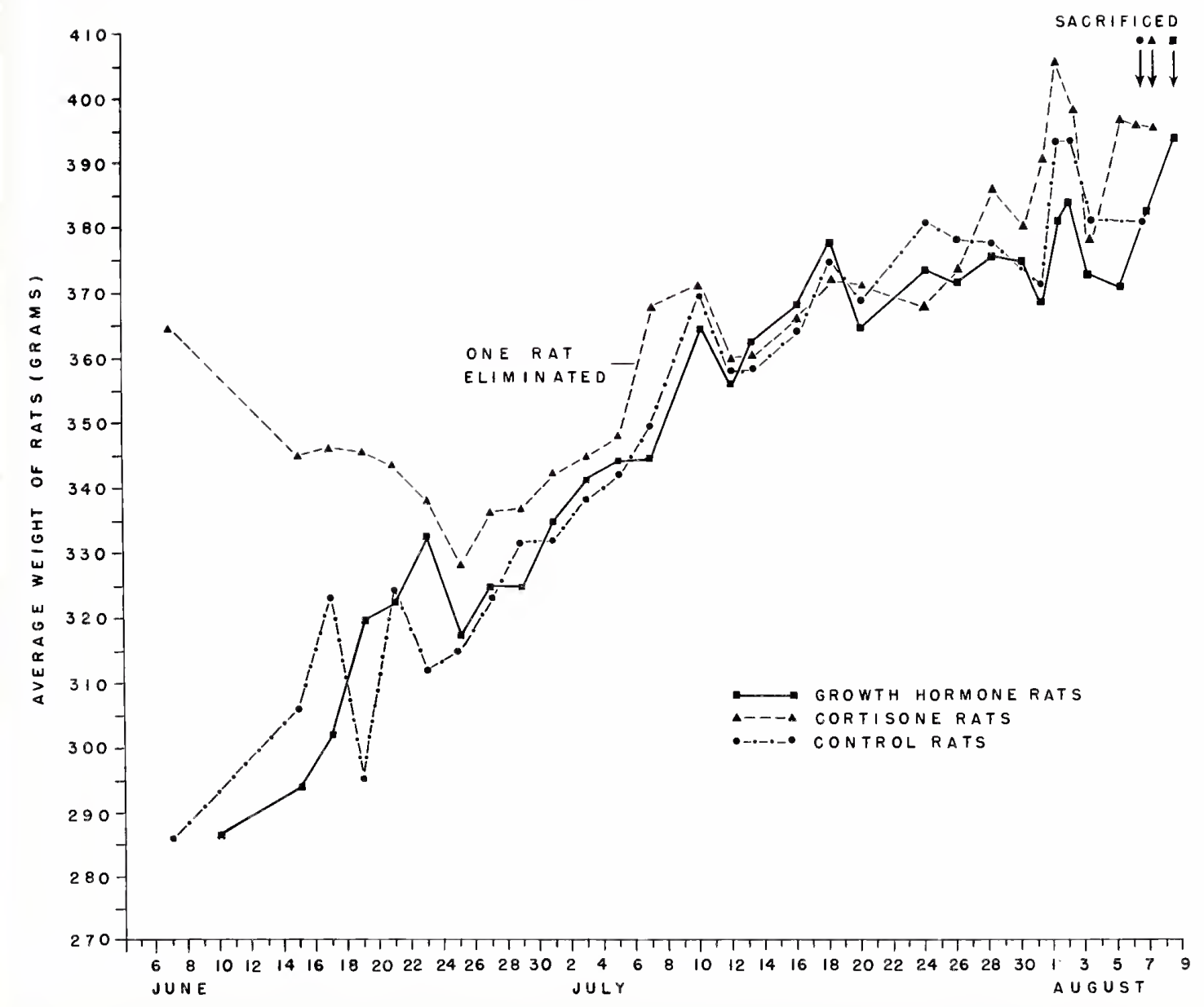

\section{Chart 2}

Recording of the average weights of control, cortisone-treated, and growth hormone-treated rats in the 8 week group. The ordinate indicates the average weight of each subgrcup. The abscissa records the successive days of the experiment. 



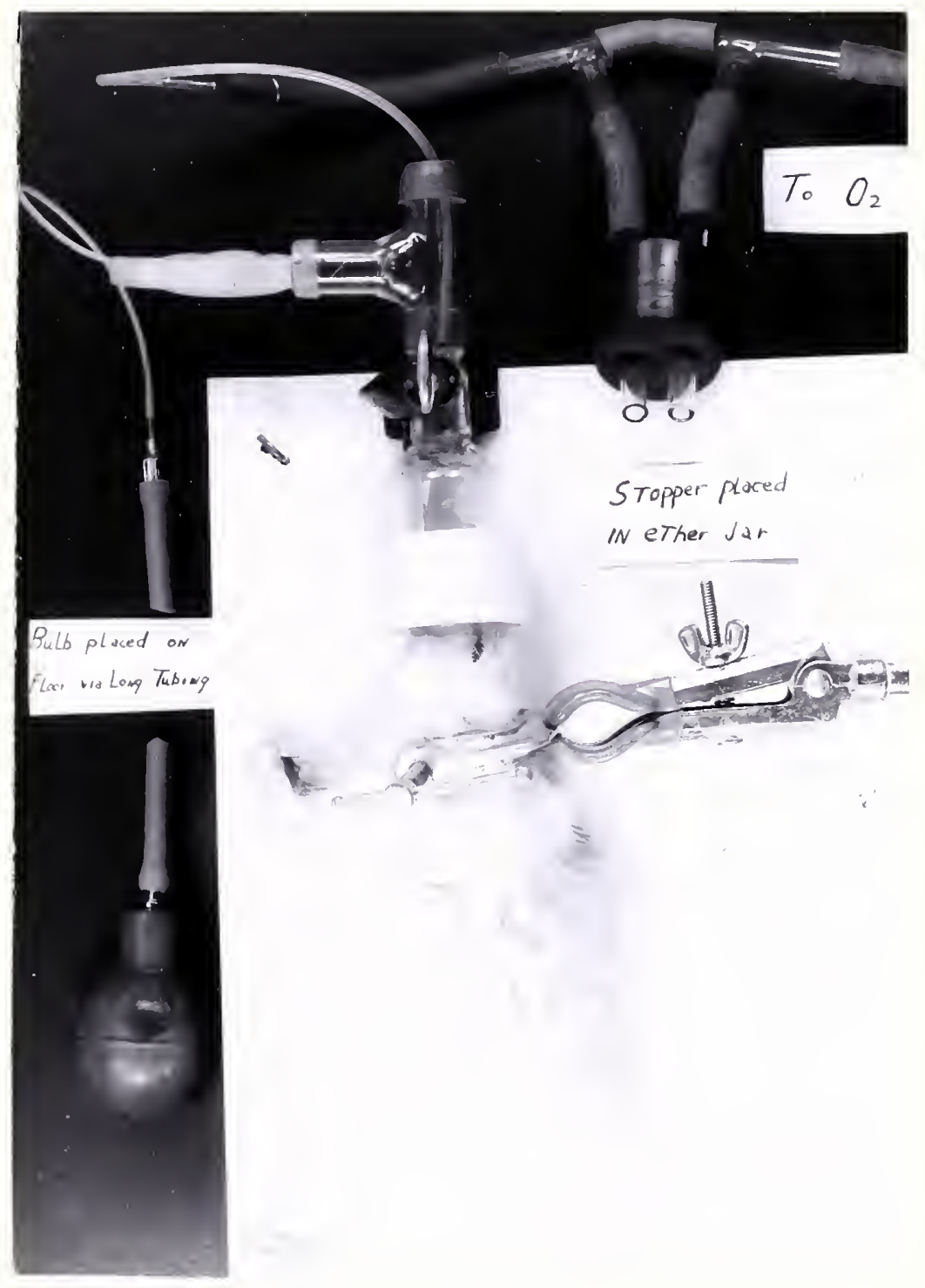

Technique for positive Pressure Anesthesia

Animal's snout placed in positive pressure chamber with rubber cuff fitting snugly around bony skull anterior to the orbits. C clamp secured on angle of mandible to prevent rat's snnut from sliding backwards out of chamber when positive pressure anplied. oxygen entered chamber through small polyethylene tube after either by-passing the ether jar or partially or completely passing through it--depending upon where rubber tubing was clamped. Positive pressure apnlied by stepping on bulb which caused the ballon valve to distend and prevented the oxygen-ether mixture from escaping the chamber. 


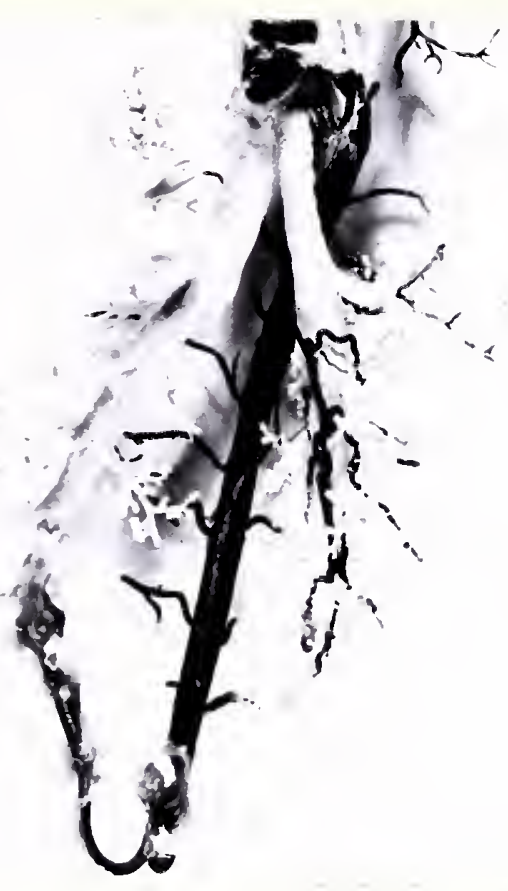

Figure 1

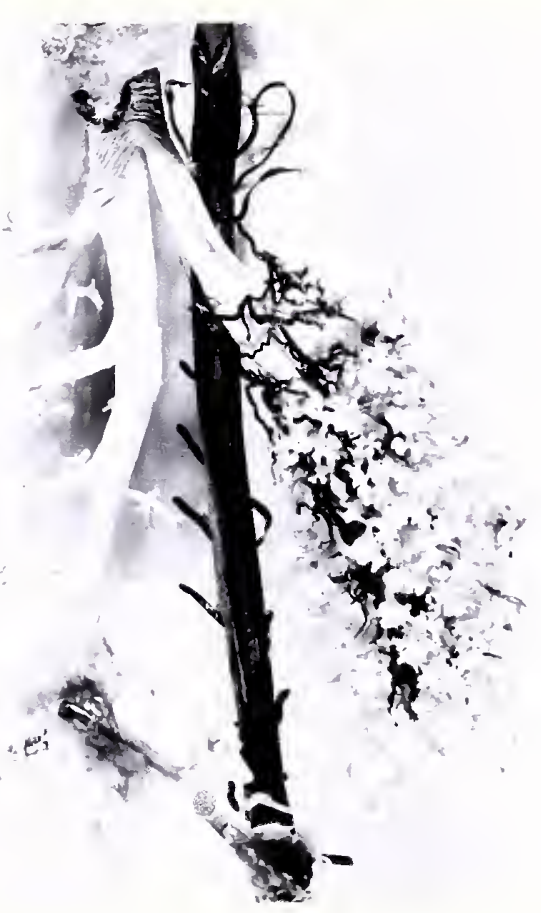

Figure 2

(See page 38 for descriotion) 



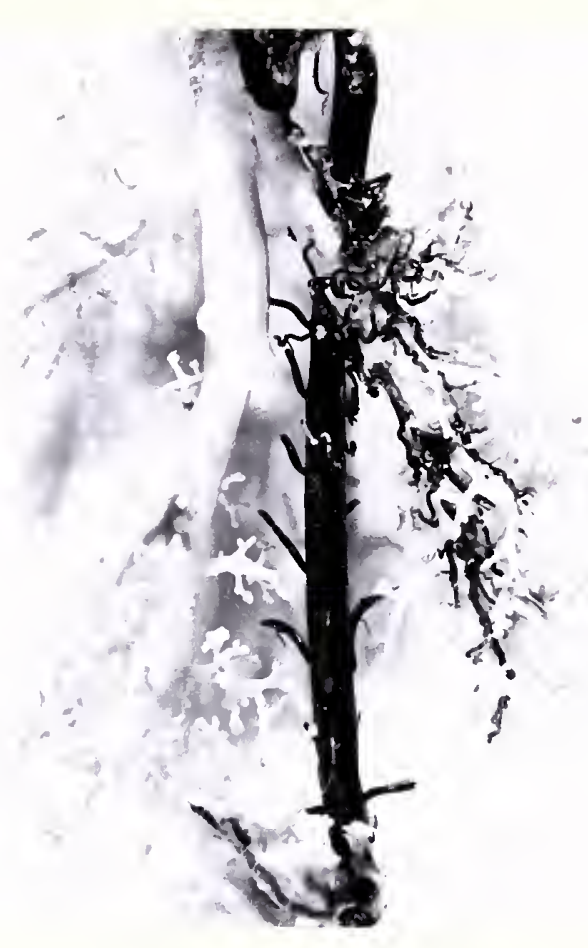

Figure 3

White casts are vinylite corrosion specimens of the tracheobronchial tree, black casts are vinylite injections of the aorta and left bronchial artery. As shown, when the abdominal aorta was injected, only the left bronchial artery subsequently filled with plastic. Figure 1 (cast no. 3) shows injection of moderately enlarged left bronchial artery. Figures 2 and 3 (casts no. 37 and 53 respective1y) demonstrate more extensive enlargements of the left bronchial arteries most frequently developed in rats receiving growth horinone. 

Table 1. Weights of Control and Experimental Groups of Rats

\section{Week Group}

Control

Cortisone

Somatropin

Av. 333

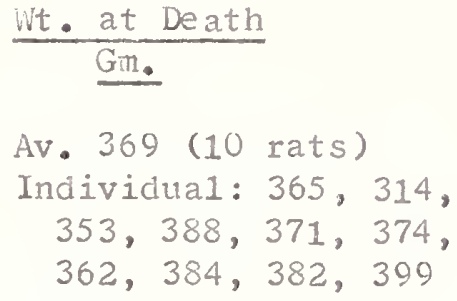

Av. 373 (9 rats)

Individual: 360,364 , $360,368,349,407$, $364,398,385$

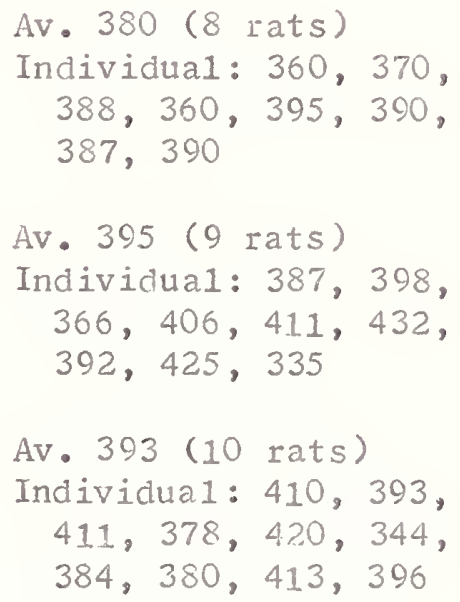


Table 2. Analysis by Visual Ranking of Collateral Development Results of Pooled Ranking by the Three Observers:

\begin{tabular}{|c|c|c|c|}
\hline Group & Sum of Ranks & $\frac{\text { Critica1 }}{\text { Foint }}$ & $\frac{\text { Interpre- }}{\text { tation }}$ \\
\hline $\begin{array}{l}\text { week control vs. } \\
4 \text { week cortisone }\end{array}$ & 44 & 51 & $\begin{array}{l}\text { Significant } \\
(P<0.05>0.01)\end{array}$ \\
\hline $\begin{array}{l}\text { week control vs. } \\
4 \text { week growth hormone }\end{array}$ & 83 & 63 & $\begin{array}{l}\text { Not Signi- } \\
\text { ficant }\end{array}$ \\
\hline $\begin{array}{l}\text { week control vs. } \\
8 \text { week cortisone }\end{array}$ & 54 & 51 & $\begin{array}{l}\text { Not Signi- } \\
\text { ficant }\end{array}$ \\
\hline $\begin{array}{l}\text { week control vs. } \\
\& \text { week growth hormone }\end{array}$ & 49 & 49 & $\begin{array}{l}\text { Significant } \\
(\mathrm{P}<0.05,>0.01)\end{array}$ \\
\hline
\end{tabular}

Table 3. Correlation Between First and Second Observations of Individual Observers by Spearman's Ranking Technigue

Correlation

Between 1st \&

2nd observation

Between 1st \&

2nd observation

Between 1st \&

2nd observation
Investigator

A

B

C
Resu1t

$98.36 \%$

$98.56 \%$

$98.06 \%$

Table 4. Correlation Between Observer's Rankings by Spearman's Ranking Technique

Investigators $\quad \underline{\text { Result }}$
A vs. C
$98.57 \%$
B.vs, C
$96.53 \%$
A vs. B
$96.68 \%$ 

Table 5. Analysis of Collateral Development by Weights of Casts

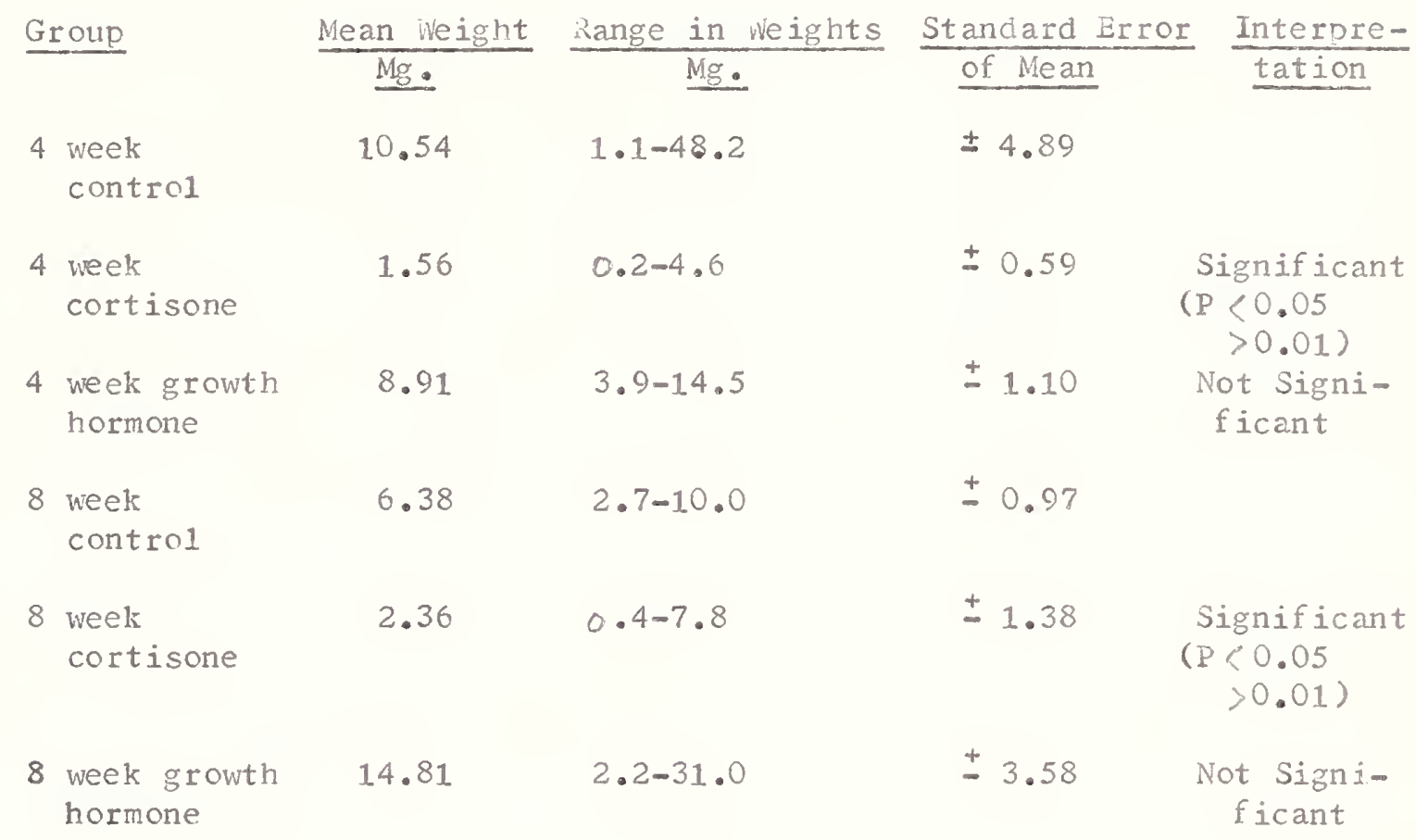

Table 6. Correlation Between Observers" Rankings and Rankings by weight

Investigator Correlation with Weight Ranking

$\begin{array}{ll}\text { A } & 95 \% \\ \text { B } & 90 \% \\ \text { C } & 93 \%\end{array}$



Table 7. Number Designation of A11 Animals

Group

4 Week Rats

A. contro1 anima1s (9)

B. cortisone animals (8)

C. growth hormone animals
Number Designation of Anima1s

$29,31,32,33,34,35,36,37,38$

$39,41,42,43,44,46,47,48$

(9) $49,50,51,52,53,54,56,57,58$

8 Week Rats
A. control animals (8)
$1,2,3,4,5,6,7,8$
B. cortisone animals (9)
$9,10,11,12,13,14,15,16,18$
C. growth hormone animals
(8) $20,21,22,24,25,26,27,28$

Tab1e 8. Visua1 Ranking of Each Observer

\begin{tabular}{|c|c|c|}
\hline$\frac{\text { bserver }}{A}$ & $\begin{array}{l}\text { First Reading } \\
\text { Division } 0: 18,11,8,29,13, \\
\text { 16,5,47,46,58,41,12 } \\
\text { Division } 1: 9,43,10,39,42, \\
\text { 26,31,54,48 } \\
\text { Division } 2: 15,4,44,35,7,36,3, \\
\text { 56,1,52,28 } \\
\text { Division } 3: 37,38,34,53,20,24, \\
\text { 14,6,51,50 } \\
\text { Division } 4: 2,33,57,49,21,27 \\
\text { Division } 5: 22,32,25 .\end{array}$ & 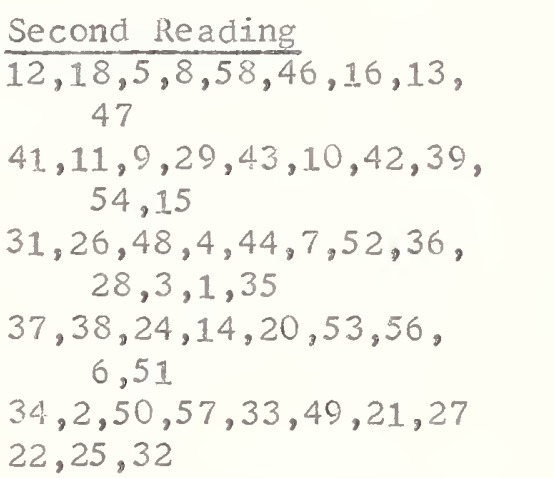 \\
\hline B & $\begin{array}{l}\text { Division } 0: 8,18,41,5,13,12,58,1 \\
\quad 29,46,16 \\
\text { Division } 1: 47,11,43,10,9,26,42 \\
\quad 39,54,48 \\
\text { Division } 2: 15,4,31,35,7,24,52, \\
\quad 44,14 \\
\text { Division } 3: 3,53,56,38,36,1,28, \\
\quad 6,20,50,37 \\
\text { Division } 4: 2,51,21,34,57,49, \\
\quad 27,33 \\
\text { Division } 5: 22,32,25\end{array}$ & $\begin{array}{l}16,5,12,46,8,58,18,13,41 \\
29,11,47,43,9,42,10,54,39 \\
4,31,15,48,7,52,24,35 \\
53,38,14,36,1,6,3,50,20 \\
44,56,37,28 \\
2,21,34,51,57,49,33,27 \\
22,32,25\end{array}$ \\
\hline C & $\begin{array}{l}\text { Division } 0: 8,13,12,5,16,18, \\
\quad 58,47,46 \\
\text { Division } 1: 41,11,10,9,43,29,42,39 \\
\quad 26,15 \\
\text { Division } 2: 48,4,31,54,44,35,7, \\
\quad 52,3,36,6,1 \\
\text { Division } 3: 28,56,24,38,2,14,37, \\
\quad 34,20,53 \\
\text { Division } 4: 57,33,51,50,21,49,27 \\
\text { Division } 5: 22,32,25\end{array}$ & $\begin{array}{l}16,12,58,18,5,46,13,8 \\
39 \quad 41,11,47,9,10,43 \\
42,29,54 \\
39,4,15,31,26,44,48,35 \\
7,28,52 \\
36,24,6,1,14,56,37,34, \\
38,20,51 \\
3,53,2,57,21,50,33,49,27 \\
22,25,32\end{array}$ \\
\hline
\end{tabular}



Table 9. Ranking of Casts by wieights

\begin{tabular}{|c|c|c|c|c|}
\hline$\frac{\text { Rank }}{0}$ & $\frac{\text { Cast Number }}{12}$ & $\frac{\text { Wts. in Miliigrams }}{0.0}$ & Subgroup & Key \\
\hline 0 & 18 & 0.0 & - & $*=4$ wh. control \\
\hline 0 & 5 & 0.0 & + & animals $=4$ wk corti- \\
\hline 0 & 8 & 0.0 & + & $\begin{array}{r}=4 \text { wk. corti- } \\
\text { sone animals }\end{array}$ \\
\hline 0 & 46 & 0.0 & 4 & $H=4$ wk $\cdot$ growth \\
\hline 0 & 58 & 0.0 & $H$ & hormule animals \\
\hline 0 & 13 & 0.0 & - & $t=8 \mathrm{wk} \cdot$ control \\
\hline 0 & 16 & 0.0 & - & animals \\
\hline 1 & 43 & 0.2 & (i) & $-m=8$ wk. corti- \\
\hline 2 & 47 & 0.3 & « & sone anima.1s \\
\hline 3 & 11 & 0.4 & $=$ & $c=8$ wk. growth \\
\hline 4 & 41 & 0.4 & 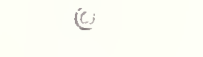 & hormone animals \\
\hline 5 & 9 & 0.5 & - & \\
\hline 6 & 29 & 1.1 & * & \\
\hline 7 & 10 & 1.3 & - & \\
\hline 8 & 39 & 1.5 & (4) & \\
\hline 9 & 48 & 1.6 & 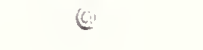 & \\
\hline 10 & 15 & 1.8 & - & \\
\hline 11 & 26 & 2.2 & ( & \\
\hline 12 & 42 & 2.3 & 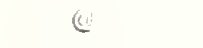 & \\
\hline 13 & 4 & 2.7 & + & \\
\hline 14 & 34 & 3.2 & $\star$ & \\
\hline 15 & 31 & 3.4 & * & \\
\hline 16 & 54 & 3.9 & H & \\
\hline 17 & 44 & 4.6 & (s) & \\
\hline 18 & 36 & 4.8 & * & \\
\hline 19 & 7 & 5.4 & + & \\
\hline 20 & 35 & 5.7 & * & \\
\hline 21 & 37 & 6.1 & * & \\
\hline 22 & 3 & 6.4 & + & \\
\hline 23 & 24 & 6.5 & ( & \\
\hline 24 & 1 & 6.6 & + & \\
\hline 25 & 38 & 6.8 & * & \\
\hline 26 & 52 & 7.0 & it & \\
\hline 27 & 2 & 7.2 & + & \\
\hline 28 & 56 & 7.2 & \# & \\
\hline 29 & 14 & 7.8 & - & \\
\hline 30 & 20 & 8.2 & ( & \\
\hline 31 & 57 & 8.8 & $\#$ & \\
\hline 32 & 28 & 8.8 & ( & \\
\hline 33 & 53 & 9.3 & $\ddot{\#}$ & \\
\hline 34 & 49 & 9.6 & $\#$ & \\
\hline 35 & 6 & 10.0 & + & \\
\hline 36 & 51 & 11.0 & \# & \\
\hline 37 & 50 & 14.5 & H & \\
\hline 38 & 21 & 15.3 & ( & \\
\hline 39 & 33 & 15.6 & * & \\
\hline 40 & 22 & 21.8 & ( & \\
\hline 41 & 27 & 24.7 & ( & \\
\hline 42 & 25 & 31.0 & ( & \\
\hline 43 & 32 & 48.2 & $*$ & \\
\hline
\end{tabular}





\section{Bibliography}

1. Liebow, A.A., Harrison, W., and Hales, M.R., Experimental pulmonic stenosis, Bull. Internat.A.M.Mus., vol. 31, 1-23, 1950.

2. Rosenberg, M.Z, and Liebow, A.A., Effects of age, growth hormone, cortisone, and other factors on collateral circulation, Arch.Patr., vol. 57, 39-105, 1954.

3. Robinson, $V_{.}$, Pathfinders in Medicine, New York: Medical Life Press, 1929.

4. Holman, E., Problems in the dynamics of blood flow: conditions controlling collateral circulation in the presence of an arteriovencus fistula, following the ligation of an artery, Surgery, vol. 26, 889, 1949.

5. North, K. A.F., and Sanders, A.G., Develoment of collateral circulation in the mouse's ear, Circulation Res., vol. 6, $721-726,1958$.

6. Winblad, J.N., Reemtsma, K., Vernhet, J.L., Laville, L.P., and Creech, 0., Etiologic mechanisms in the develonment of collateral circulation, Surg.,vo1. 45, 105-i17, 1959.

7. Mulvihil1, B.A., and Harvey, S.C., Studies on collateral circulation; thermic changes after arterial ligation and ganglicnectomy, J.C1in.Invest., vo1. 10, 423-429, 1931.

8. Reid, M.R., Studies on abnormal arteriovenous comunications, Arch.Surg., vo1. 10, 998-1.009, 1925.

9. Holman, E., Problems in the dynamics of blood flow: conditions controlling circulation in the presevce of an arteriovenous fistula, following the ligation of w artery; in Bier, Virchow's Arch.f.Path.Anat, vol. 147, 256, 44.4, 1897.

10. Lewis, T., Acijustment of b100dflow to affected limb in arteriovenous fistula,. Clin.Sc., vol. 4, 277, 1940.

11. Moon, H.D., Inhibition of scmatic growth in castrate rats with pituitary extracts, Proc.Soc.Exner.Biol.8Med., vol. 37, 34-36, 1937.

12. Asling, C.W., Reinhardt, W.O., and Li, C.H., Effects of adrenocorticotropic hormone on body growth, visceral proportions, and white blood cel1 counts of normal and hypophysectomized male rats, Endocrinology, vol. 48, 534-547, 1951 .

13. Ghadially, F. N., and Green, H.N., Effect of adrenal hormones and adrenalectony on mitotic activity, Brit.J.Jxper.Jath., vo1. $3 \varepsilon$, $100-110,1957$.

14. Castor, C. W., and Baker, B.L., The local action of adrenocortical steroids on epidermis and connective tissue of the skin, Endocrinology, vo1. 47, 234, 1950 .

15. Taubenhaus, M., and Armomin, G.D., The effects of the hypophysis, thyroid, sex steroids, and the adrenal cortex upon granulation tissue, J.Lab.8C1in.Med., vo1. 36, 7, 1950.

16. Shapiro, B., Taylor, B., and Taubenhaus, M., I.ocal effects of cortisone on granulation tissue and the, role of depervation, and ischemia, Proc.Soc.Exper.Bic1.8med., vol.76, 854, 1951.

17. Spain, D.M., Molomut, N., and Haber, A., The effect of cortisone on the formation of granulation tissue in mice, Am.J.Path., vo1. 26, 710-711, 1950 . 

18. Spain, D.M., Molomut, N., and Haber, A., Biologic studies on cortisone in mice, Science, vo1, 112, 335-337, 1950.

19. Howes, E.L., Plotz, C.M., Blunt, J.W., Jr., and Ragan, C., The retardation of wound healing by cortisone, Surgery, vo1.28, $177-181,1950$.

20. B aker, B.I.., and Witaker, W.I., Interference with wound healing by local. action of adrenocortical steroids, Endocrinology, vo1. $46,544,1950$.

21. Ragan, C., Howes, E.I., Plotz, C.M., Meyer, K., Blunt, J.w., and Lattes, R., The effect of ACTH and cortisone on connective tissue, Bu11. New York Acad.Med., vo1. 26, 251, 1950.

22. E lunt, J. W., Plotz, C.M., Lattes, R., Howes, E.L., Neyer, K., and Ragan, C., Effects of cortisone on experimental fractures in the rabbit, Frcc.Soc.Exper.Bio1. Enied., vo1. 73,678-681, 1950.

23. Plotz, C.M., Howes, E.I., Meyer, K., Lattes, R., and Ragan, C., The effect of hyperadrenal state on connective tissue, Am. J. Path., vo1. 26, 709, 1950.

24. Eaxter, H., Schiller, C., and witeside, J.H., The influence of ACTH on woind healing in man, Plast.\&Reconstruct.Surg., vo1. 7, 85-99, 1951 .

25. Creditor, M.C., Bevans, M., Mundy, W.I., and Ragan, C., Effect of ACTH on wound healing in humans, Proc.Soc.Exper.Biol.aMled., vo1. $74,245-247,1950$.

26. Scow, R.O., Effect of growth hormone and thyroxine on growth and chemical composition of muscle, bone and other tissues in thproidectomized-hypophysectomized rats, Am.J.Physio1.., vo1. 196, 859-865, 1959 .

27. Liebow, A.A., Hales, M.R., Bloomer, W.E., Harrison, $W_{\bullet}$, and Lindskog, G.E., Studies on the lung after ligation of the pulmonary artery; anatcmical changes, Am.J.Path., vol. 26, $177,1950$.

28. Berry, J.L., The relation between bronchial and pulmonary circulations in the human 1 ung, investigated by radiopague injections, Quart.y.Exper.Physio1., v01.24, 305, 1935.

29. Miller, H.S., The vascular sunply of the bronchial tree, Am.Rev. Tuberc., vo1. 12, 87-93, 1925 .

30. Ver1oop, M. C., On the arteriae bronchiales and their anastomosing with the arteria pulmonalis in some rodents; a micromanatomical study, Acta Anat., voi. 7, 1-32, 1949.

31. Weibe1, E.R., Early stages in the development of collateral circulation to the lung in the rat, Circul.Res., vol. 8, $353-376,1960$.

32. Rakstit, P., Communicating blood vesse1s between bronchial and pulmonary cjrculation in the guinea-pig and rat, uart.J.Exper. Physio1., vol. 35, 47-53, 1949.

33. Marchand, P., Gilroy, J.C., and Wilson, V.H., An anatomical study of the bronchial vascular system and its variations in disease, Thorax, vol. 5, 207-221, 1950.

34. Packard, G. $\mathrm{B}_{\bullet}$, and Waring, J.J., Arteriovenous fistula of the lung treated by lisation of the nulmonary artery, Arcis.Surg., vol. $6,725-740,1948$.

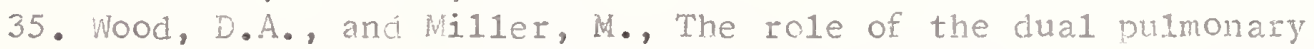
circulation in various pathologic conditions of the lungs, J.Thor.Surg., vo1. 7, 649-670, 1937-38. 

36. Wright, R.D. The blood supply of abnomal tissues in the 1 ung, J.Path.Bact., Iond., vol. 47, 489-499, 1938.

37. Liebow, A.A., Hales, M.R., and I, indskog, G.E., Enlargement of the bronchial arteries, and their anastomoses with the pulmonary arteries in bronchiectasis, Am.J.Path., vol. 25, 211-231, 1949.

38. Liebow, A.A., The bronchopulmonary venous collateral circulation with special reference to emphysema, Am.J.Path., vol. 29, $251-289,1953$.

39. Liebow, A.A., Loring, W.E., and Felton, II, The musculature of lungs in chronic pulmonary disease, Am.J.Patt., vol. 29, $885-911,1953$.

40. Roosenberg, J.G., and Deenstra, H., BronchiaI-pulmonary vascular shunts in chronic pulmonary affections, Dis.Chest., vol. 26, $664-671,1954$.

41. Mallory, T.R., The vathogersis of bronchiectasis, New En Iand j. ived., vol. 237, 795-798, 1947.

42. Liebow, A.A., Hales, M.R., Harxison, N., Blooner,.. E., and Iindskog, G.t., The genesis and functional imblications of collateral circulation of the Iungs, Vale J.Bicl. dived., vn1. 22, 637-650, 1949-50.

43. Hales, M.R., and Liebow, A.A., Collateral Circulation to the lungs in congenital nulmonic stenosis, Bull. Internat. A.M.Mus., vo1. $28,1-22,1948$.

44. Rich, A.R., A hitherto unrecognized tendency to the development of widestread nulmonary vascular obstruction in patients with congenital nulmonary stenosis (tetralosy of Fallot), Bul1. Johns Honkinstosp., vol. 82, 389-402, 1948.

45. Virchow, R., Virchow's Arch.f.Path.Anat., vo1. 1, 1, 1847; vol. $3,427,1851$.

46. Schlaepfer, K., Ification of the pulmonary artery of one lung with and without resection of the phrenic nerve, Arch. Surg., vo1. 9, 25-94, 1924.

47. Vidone, R.A., Kline, J.L, Pitel, M., and Liebow, A.A., The application of an incuced bronchial collateral circulation to the coronary arteries by cardio-pneumonopexy, II. Hemodynamics and the measurement of collateral filow to the myocardium, Am.J.Path., vol. 32, 897-914, 1956.

48. Bloomer, W. E., Harrison, W., Lindskog, G.E., and Liebow, A.A., Respiratory function and blood flow in the bronchial artery after ligation of the pulmonary artery, Am.J.Physiol., vol. $1.57,317,1949$.

49. Lieborn, A.A., Hales, M.R., Bloomer, W.E., Relation of bronchial to pulmonary vascular tree, Pulmonary Circulation, New York: Grune and Stratton, 1959, 79-98.

50. Shedd, D.P., Alley, R.D., and Lindskog, G.E., Cbservations on the hemadynamics of bronchial pulmonary vascular communications, J.Thor.Surd., vo1. 22, $537,1951$.

51. Hacrison, $W_{.}$, and Liebow, A.A., Gas exchange in the lung denrived of pulmonary arterial sunnly, Yale J.Rio1., vol. 22, 251-261, 1950 .

52. Roh, C.E., Greene, D.G., Himme1stein, A., Humphreys, G.H., III, and BaIdwin, E.deF。, Cardiopulmonary function studies in a patient with ligation of the left pulmonary artery, Am.J.Med., vo1. 6, 795-798, 1949 . 

53. E11is, F.H., Grinclay, J.H., and Edwards, J.E., The bronchial arteries: structural changes after division of the rat's left pulmonary artery, An.J.Path., vol. 28, 89-96, 1952.

54. Holman, E., Reichert, F.I., and Mathes, M.E., A study of the bronchial,pulmonary, and lymphatic circulations of the lung under various pathologic conditions experimentally produced, J.Thor.Surs., vol. 1, 339-362, 1932 .

55. Porter, C.B., and Sma11, J.T., A method for intrathoracic operation on the rat, Proc.Soc.Exper.Bio1.8ured., vo1. 64, $239-241,1947$.

56. Loring, N.E., A method of positive pressure anesthesia for the rat, Proc.Soc.Exper.Bì01, \&Med., vol. 79, 658-660, 1952.

57. Narat, J.K., Loef, J.A., and Narat, M., On the preparation of multi-colored corrosion specimens, Anat.Rec., vol. 64, $155-160,1936$.

58. Puckett, W.O., and Neumann, C.P., The vinylite corrosion technique, Anat.Rec., vn1. 78, 1.05-111, 1940.

59. I,iebow, A.A., Hales, M.R., Lindslog, G.E., and Bloomer, W.E., Plastic demonstrations of nulmonary pathology, J.Tech. Mieth., vo1. $27,116-129,1947$.

60. Moolten, S.E., A simnle annaratus for fixation of lungs in the inflated state, Arch.Path., vol. 20, 77-80, 1935.

61. inite, C., The use of ranks in a test of significance for comparing two treatments, Biometrics, vo1. 8, No. 1, 1952.

62. Croxton, F.E., Elementary Statistics with Applications in Medicine, New Y crk: Prentice-Ha11, 1953, 140-143. 






\section{YALE MEDICAL LIBRARY \\ Manuscript Theses}

Unpublished theses submitted for the Master's and Doctor's degrees and deposited in the Yale Medical Library are to be used only with due regard to the rights of the authors. Bibliographical references may be noted, but passages must not be copied without permission of the authors, and without proper credit being given in subsequent written or published work.

This thesis by has been used by the following persons, whose signatures attest their acceptance of the above restrictions.

NAME AND ADDRESS

DATE

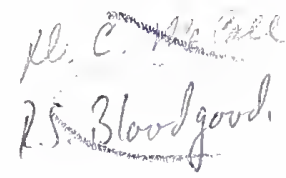


